\title{
Application of ADI in a crushed coal delivery and filtering system
}

\section{Arron Rimmer}

ADI Treatments Limited, Doranda Way, West Bromwich B714LE, UK

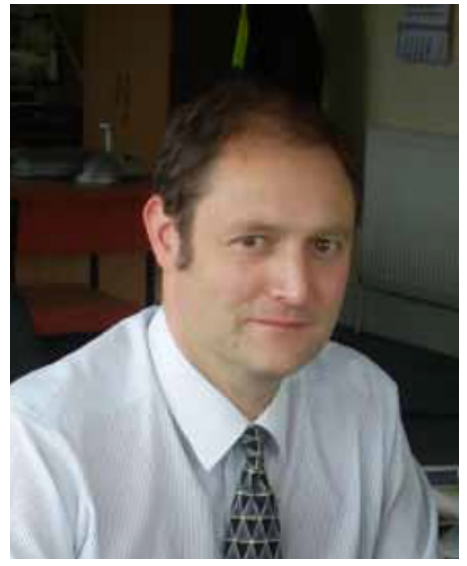

\section{*Arron Rimmer}

He attended Manchester University, studying metallurgy at The Manchester Materials Science Centre. On completion of his degree, he remained at the university where he completed a masters degree in austempered ductile iron and doctorate in austempered compacted graphite iron. On leaving university in 1994, he joined Manganese Bronze Components Limited as an R\&D engineer, working on various projects including the development of sintered automotive camshafts. Three years later, he joined ADI Treatments Ltd. as their Business Development Manager, before becoming a Director and Shareholder in 1999. He is a member of the Institute of Cast Metals Engineering, and a Company Member of the Contract Heat Treatment Association. His work brought him the Final Year Metallurgy Award and the British Foundry Medal.

E-mail: arron.rimmer@aditreatments.com

Received: 2019-11-25

Accepted: 2020-03-04

\begin{abstract}
Up to one million metric tonnes of coal are crushed each year. The crushed coal continually flows through a pipe delivery system at a rate of up to 60 tonnes per hour. In a nitrogen rich environment, the delivery system is constantly under pressure of nearly 9 bar. Filters are used in each pipe delivery system to prevent incorrectly sized material and 'foreign materials' from entering the blast furnace. Any incorrect material is held up long enough to be broken-down before becoming small enough to pass through the filter. In the past, foreign materials simply blocked the system. The aforementioned environment creates materials' applications issues. This paper describes how ADI is used to meet these challenging demands in a crushed coal delivery and filtering system. The work described in this paper has resulted in a number of new applications using ADI and CADI materials which are now operating in 'waste to energy incineration' plants, aluminum production plants, iron sinter and iron slag processing application, such as rotary crusher, cage crusher, curved door, etc.
\end{abstract}

Key words: austempered ductile iron; austempering; carbidic austempered ductile iron; 3D printing

CLC numbers: TG143.5; Document code: A; Article ID: 1672-6421(2020)02-178-05

Carbidic Austempered Ductile Iron (CADI) has been developed and used in industrial application for nearly 20 years ${ }^{[1-4]}$. The most common industry that is using CADI is the agricultural industry ${ }^{[1]}$. Some other industries are starting to use CADI more regularly and this paper shows one such example used in the production of steel.

Up to one million metric tonnes of coal is unloaded at the docks each year. It is conveyed to the three crushing machines; the largest volume goes to the rotary crusher and the rest is processed by one of the two cage crusher systems. After the conveyor, coal is gravity fed into the crushers and when it reaches the correct particulate size, the coal rises into the collection system. The coal is dried before passing to the silos (Fig. 1). Once crushed, the coal could travel up to a maximum of 3 miles (approximately $5 \mathrm{~km}$ ). There are three sets of filters along this journey as the purity and grain size are essential for the profitable production of steel.

Coal is crushed and has a fine particulate size. It moves around the pipework under pressure in a nitrogen rich environment. The customer had explained that other materials have been known to "fall into the system". These other materials could range from pieces of steel or wood to pieces of lost safety clothing and PPE. Similar items had been found in the system previously; either blocking the filters or causing the filter to break up and block the injection system further along.

Any new filter (screen and trash cone) will have a series of conditions that must be met:

(1) The flow rate of the coal must remain the same, 60 tonnes per hour at 9 bar;

(2) The parts have to be welded together with a stainless steel 'body' and a base plate prior to installation;

(3) The outer dimensions cannot be increased as the part fits inside the existing pipe work;

(4) New material will have to last at least twice as long (over 13 weeks), and comply with the existing maintenance schedules. 


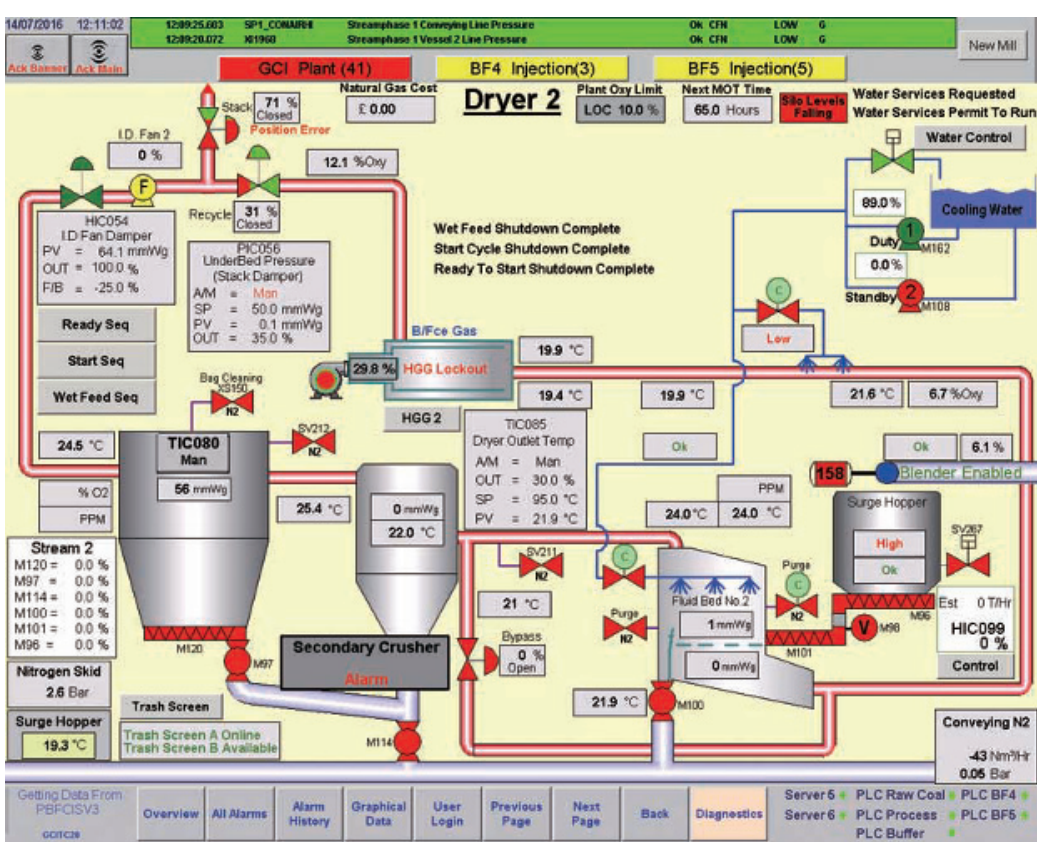

Fig. 1: A schematic of the dryer system

The coal filters were produced from an $8 \mathrm{~mm}$ thick stainless steel plate with laser cut $14 \mathrm{~mm}$ square holes with each hole separated from the next by just $6 \mathrm{~mm}$. The plate is coiled into a cylinder and welded together. At one end of the cylinder, a cone is welded into place. The tip of the cone was solid EN24 (36CrNiMo4), the body of the cone was produced in the same perforated steel as the cylinder. The whole fabrication is held, with the tip pointing down, within the coal delivery pipes as the coal is blown upwards, through the screen. This product would last up to 6 weeks. In Fig. 2, the first design is shown. It shows stainless steel rods being used rather than laser cut plate.
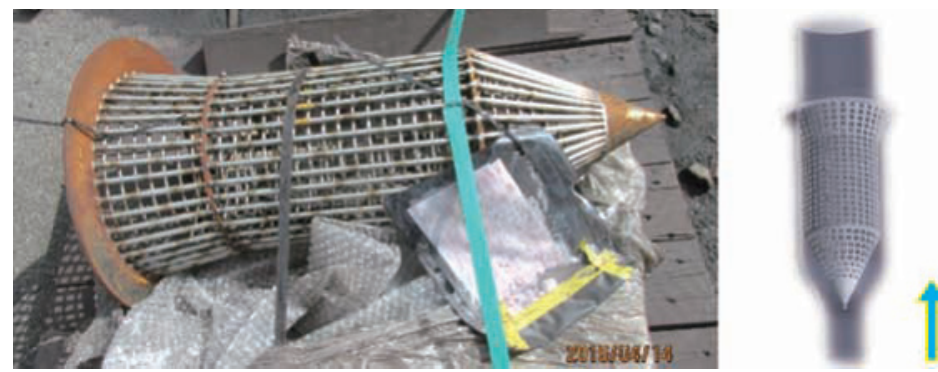

Fig. 2: Fabricated filter (a) and schematic of the installation (b)

New design parameters included:

(1) The trash cone holes have to be square and perpendicular to the outer radius of the cone;

(2) Each hole has to have minimum radii in the corners for material flow;

(3) The section must be $8 \mathrm{~mm}$ or less due to the on-site handling and clearances around the pipe.

With all of these considerations taken into account, a casting model was designed and created, see Fig. 3.

\section{Production}

\subsection{The mould}

A traditional pattern for sand cast moulding would not be suitable as a traditional core could not be stripped. A 3D sand printed mould was designed. The design would include the runner system and print direction for the best

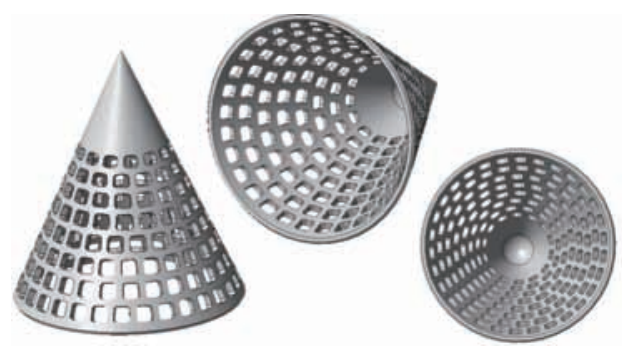

Fig. 3: A 3D model (schematic) of the ascast filter

result. The design allows for the use of a tubular runner system, filling the cavity from beneath and running metal into the cone tip first. The solid cone tip had to be redesigned to avoid possible 'shrinkage' issues. A three-part mould was designed.

To maintain overall accuracy of the finished part, the mould was not to be surface treated; casting is done directly on to the surface of the printed mould. The selection of the grain size and sand binder is critical for this to be successful.

Two identical moulds were printed - one to be cast and austempered to EN1564 Grade 14001 and another one to be cast and austempered to CADI.

\subsection{Casting}

Each mould was assembled and surrounded or packed in a moulding frame with a pouring bush. At this time, the two moulds have been printed for just over 2 weeks. Since this initial work, the printed moulds have been used over 24 weeks while with the same positive results. In normal production, many cores and moulds degrade over a shorter period of time leading to defects in casting.

Each furnace melt was $1,500 \mathrm{~kg}$, using a basic pig iron and profile steel blend. Alloys were added while in the furnace and verified by electron spectrograph prior to final tapping out. The tapping temperatures were approximately $1,500{ }^{\circ} \mathrm{C}$. Inoculation and treatment both took place within the same pouring ladle.

Once the casting had cooled and was knocked-out, the runner was cut-off just above the cone top. No other dressing or fettling was necessary. A thin ring of weld was applied around the lower circumference of the cone. Further details of the weld are proprietary and will not be discussed within this paper.

Initially, two cones were cast, one in ADI 1400 (Grade 4) and a second in CADI. The ADI cone was welded onto a stainless steel cylinder and installed in the system in February 2014. 
The cone was inspected in March, May, July and September before being removed from the system late in October 2014.

\subsection{Austempering}

Castings were austempered in a standard universal batch quench austemper (UBQA) furnace, austenitized under a $\mathrm{C}$ rich atmosphere, and were quenched in salt (50/50 Potassium Nitrate / Sodium Nitrite). Temperatures and times were selected based on the alloy content, section thickness and required ADI grade. For hardenability, alloying with $\mathrm{Cu}$ only was required $(0.80 \%)$. Austenitizing was carried out at 890 ${ }^{\circ} \mathrm{C}$ and austempering at $280{ }^{\circ} \mathrm{C}$. Although cracking is highly unlikely in austempering, due to the novel use of pre-welding, plus the thin section which could contain carbide through the casting process, nondestructive testing (NDT) was performed post austempering to ensure that no cracks formed. This step was even more critical in the CADI where the material is inherently more brittle due to the presence of a controlled volume of carbides.

Both the ADI and the CADI were processed with the same parameters, aiming for Grade 4 ADI (ADI 1400). There are no standards for CADI as this material has been developed solely for hardness and wear resistance. All subsequent cones were produced in Grade 4 ADI (ADI 1400) achieving a surface hardness ranging from 427-447 HBW.

\subsection{Assembly}

The first cone was delivered to the customer in early February 2014. It was welded into place on the body of the filter assembly as shown in Fig. 4.

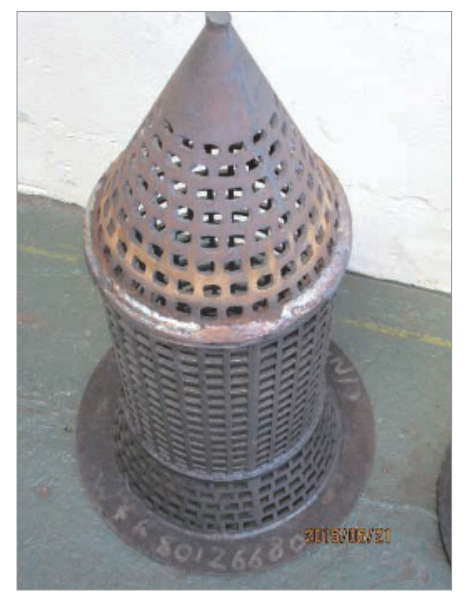

Fig. 4: A fully assembled $14 \mathrm{~mm}$ trash screen and cone. The cone is made of Grade 4 ADI (ADI 1400), welded on the top of a $\mathbf{3 1 6}$ stainless steel body and base

\section{Results}

The first used cone is shown in Fig. 5. The casting was tested to near destruction. A product life of $30+$ weeks was achieved with a good safety margin. This was more than twice the target working life.

The hardness is checked at a flat spot at the tip of the cone. The initial microstructure was not evaluated as it would destroy the test component. It was impossible to judge how

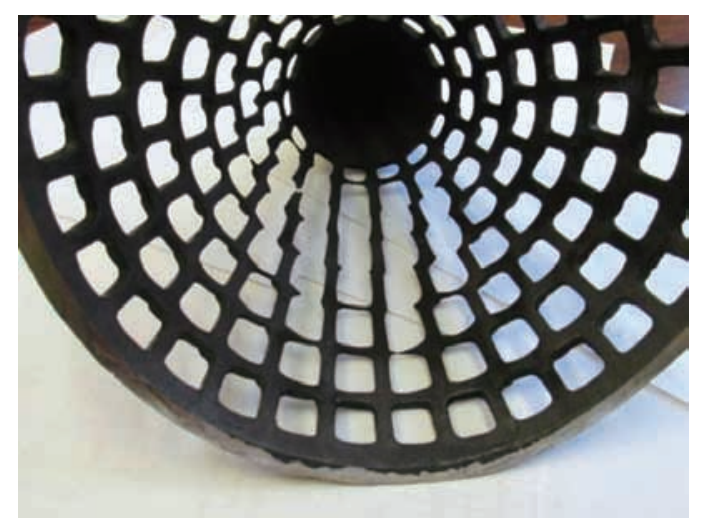

Fig. 5: First used ADI cone after 30+ weeks in service

long the part would last. The customer was regularly asked if the cone was still 'there'? In October, the cone was removed and microstructural analysis became possible. Representative microstructures are shown in Figs. 6-9. The performance could be fully assessed before operational decisions were reached.

After the test results of the first cone were achieved, using this product fully within the entire production system immediately became the ambition and new target. During the initial trial, fewer blockages in the system were recorded; resulting in less unscheduled down time. The extended working life is also beneficial in that it eases the workload at the regular maintenance stops.

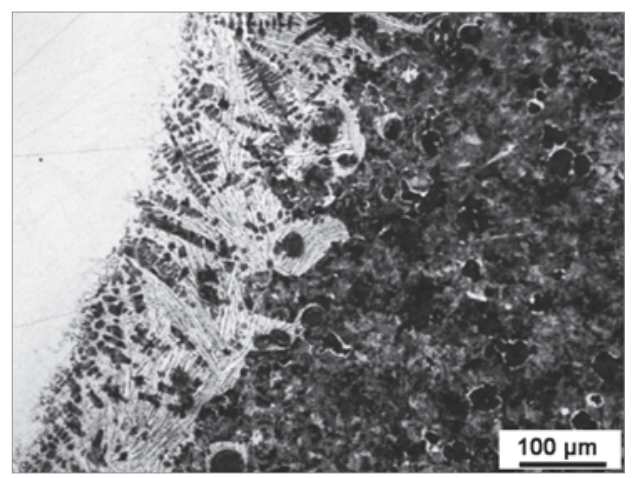

Fig. 6: Microstructure adjacent to the weld. The penetration of the weld into the casting as well as a heat affected zone was observed. The area to the far right is Grade 4 (ADI 1400), etched with nital

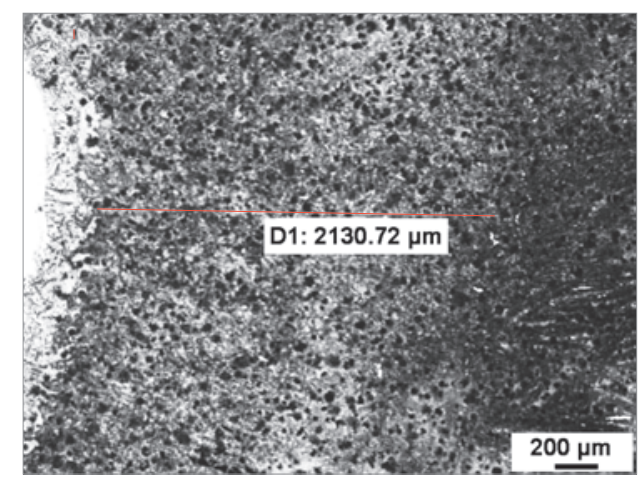

Fig. 7: A boundary is visible where weld penetration has damaged the graphite structure. Beyond the weld penetration area, there is a heat affected zone. Graphite nodules are still clearly present (etched with nital) 


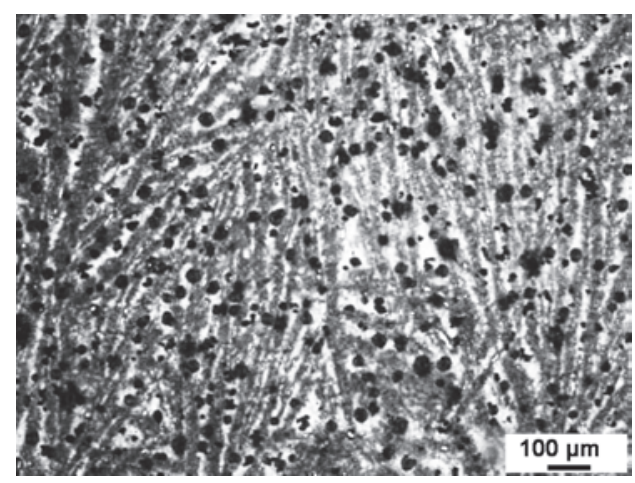

Fig. 8: A good nodule count of standard shapes and sizes

\section{Application - coal filter and delivery system}

There are 2 trash cone assemblies operational at any time. A second set (or back up filters) is used when maintaining the first set. The schematic in Fig. 10 shows both " $1 \mathrm{~A}$ " and " $2 \mathrm{~A}$ " are online while "1B" and "2B" are offline.

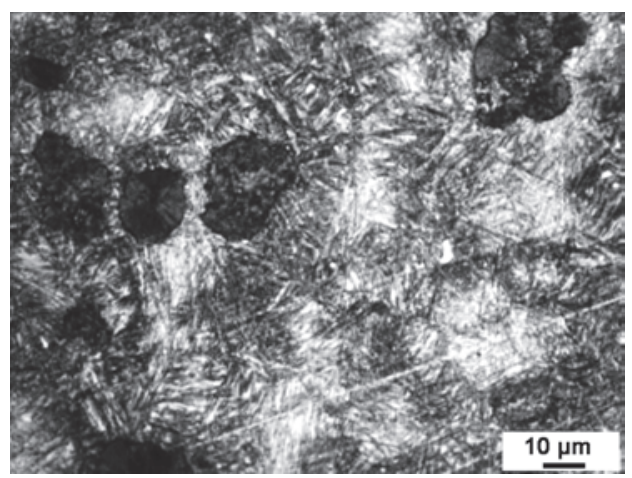

Fig. 9: Base microstructure of the austempered cone, etched with nital

The combination of turbulence and the flow of coal has created a surface pattern that can be seen in Fig. 11. The flow of coal creates a 'rifling' effect and greater wear is evident on one side of each cone. The cone to the right of the picture in Fig. 11 has been in operation for longer than 26 weeks, while the cone to the left has been operating for the planned time of 26 weeks. The requirement for the cone to be reliable, robust and flexible, is demonstrated.

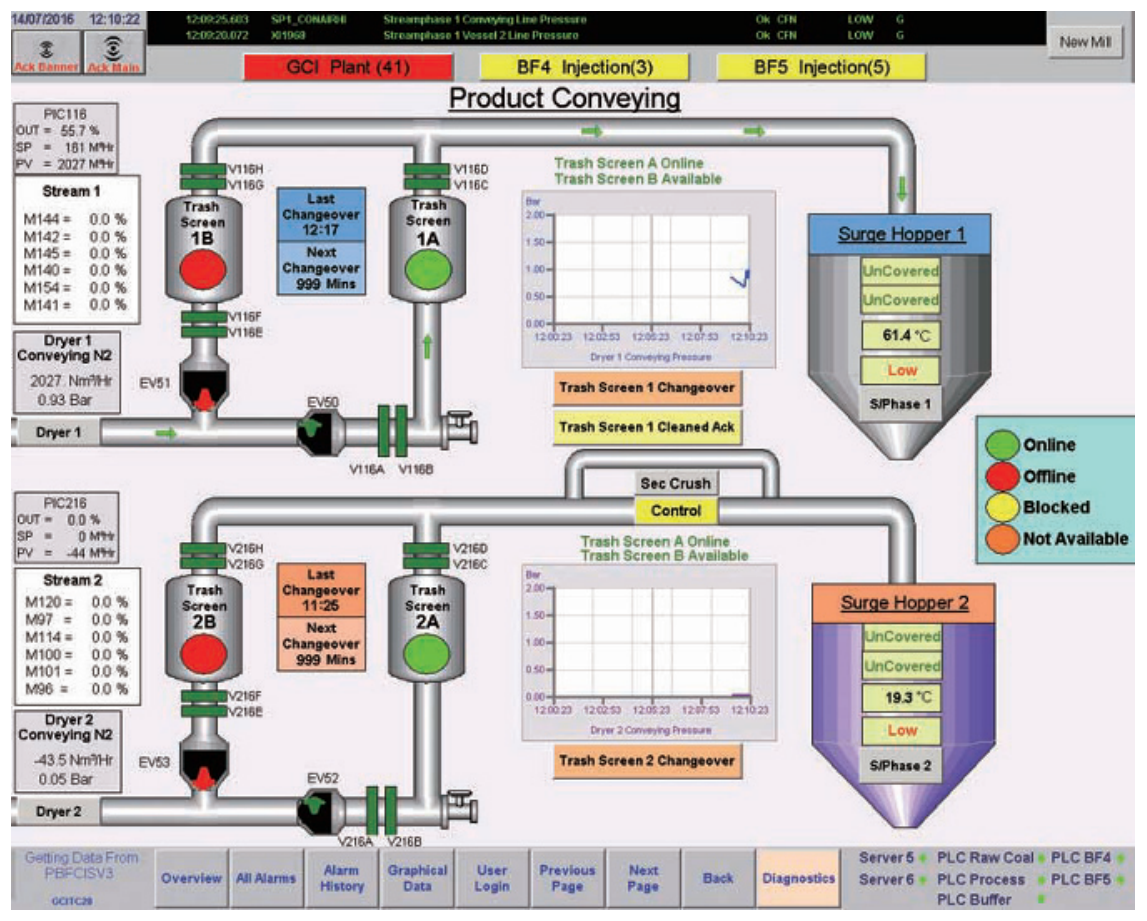

Fig. 10: A schematic of the coal filter system

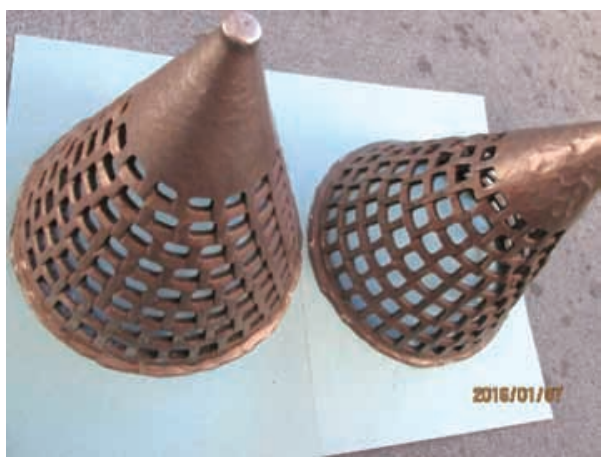

Fig. 11: Two used trash cones showing the pattern created by the flow of the coal dust. Note that the hardness test mark at the top of the cone still can be seen
The decision was made to replace each trash cone as part of a routine planned maintenance schedule. This is generally every 26 weeks. This equates to approximately 262,000 tonnes of coal passing over and through each cone. Every time the trash cone filter is replaced, a full risk assessment is completed. This risk assessment could take nearly one day to complete.

The trials of the ADI trash cone met and surpassed all expectations. As a consequence, the CADI cone was considered, but not tested. Additional ADI filters have been operating over the last 5-6 years. A further 'birds nest' filter has been developed and was installed in 2016.

The work described in this paper has resulted in a number of 
new applications using ADI and CADI materials which are now operating in 'waste to energy incineration' plants, aluminum production plants, iron sinter and iron slag processing applications. Figures 12-15 show examples of these new and exciting applications.

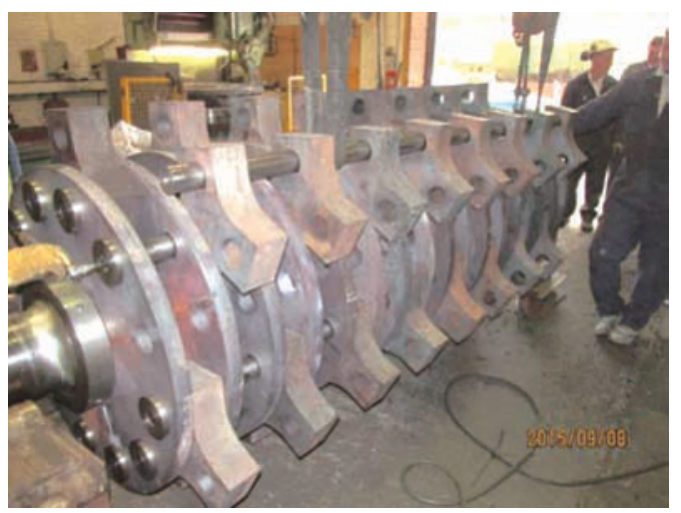

Fig. 12: A CADI rotary crusher - 17 centre spacers cast and machined in CADI. Each part is $350 \mathrm{~kg} .48$ trihammers, cast in ADI 1,400. Each part is $55 \mathrm{~kg}$. The centre shaft is $5.3 \mathrm{~m}$ long. The shaft has a key, 50 $\mathrm{mm} \times 25 \mathrm{~mm} \times 2,750 \mathrm{~mm}$. Each spacer has to slide along this key

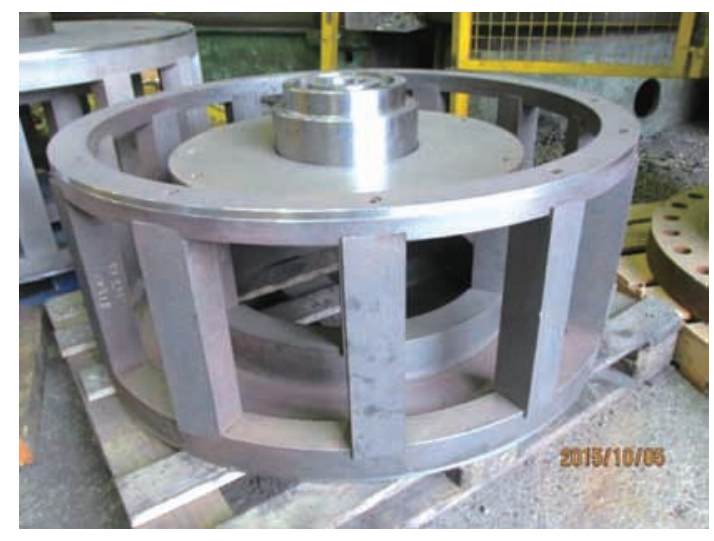

Fig. 13: An ADI cage crusher application - This is the smaller half of the cage crusher set. The hammers are ADI 1,400 Grade 4. The outer ring and base are ADI 900 Grade 1. The two cages rotate in opposite directions. Each cage is dynamically balanced at $720 \mathrm{rpm}$

\section{Summary}

The ADI trash cones far exceeded the target lifetime of 13 weeks. The supply of ADI cones has continued since October 2014. This success has allowed the use of ADI cast and machined parts to grow; and as a result, further applications of ADI are now operating at Tata Steel, Port Talbot. In October 2015, the first machined CADI parts were put into production. There are currently 10-12 ADI / CADI products either in operation or under development. The work described in this paper resulted in a number of new applications using ADI and CADI materials which are now operating in 'waste to energy incineration' plants, aluminum production plants, iron sinter and iron slag processing application, such as rotary crusher, cage crusher, curved door, etc.

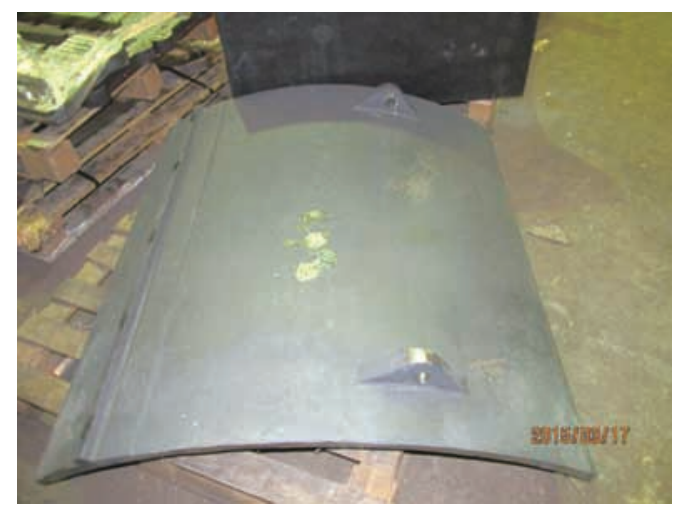

Fig. 14: An ADI 1,200 mm curved door - This is 4 feet wide and weighs $240 \mathrm{~kg}$. The door is cast in ADI 1,400 Grade 4. Over $60,000 \mathrm{~kg}$ of coke or iron sinter impact this door every $8 \mathrm{~min}$. It is first welded in position and then bolted in place. The product was in service for nearly 3 years before the need for a replacement

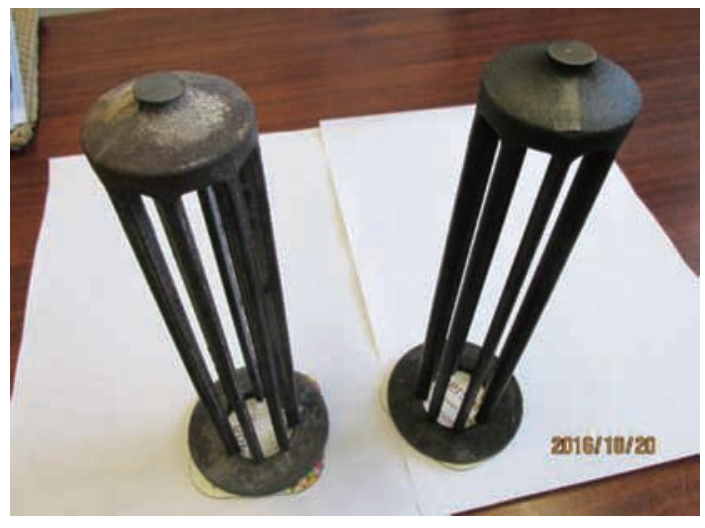

Fig. 15: A new, thin wall ADI design - wall section are $4 \mathrm{~mm}$ and $5 \mathrm{~mm}$ with strict $12 \mathrm{~mm}$ gaps. Metal grade ADI 1,400 (Grade 4)

\section{Acknowledgements}

Special thanks to the Boro Foundry Ltd, Lye, United Kingdom, and the TATA Steel UK Ltd, Port Talbot, United Kingdom.

\section{References}

[1] Arron Rimmer. Furnace is key to CADI solutions. Foundry Trade Journal, 2006, 180 (3): 58-59.

[2] John Keough, et al. Carbidic austempered ductile iron. Applied Process Inc, 2000.

[3] Kathy Hayrynen, et al. Carbididc austempered ductile iron (CADI) - The new wear material. Applied Process Inc, 2003.

[4] Kathy Hayrynen, et al. Wear properties of ADI. Applied Process Inc, 2005.

The paper was published in the Proceedings of the 2nd Carl Loper Cast Iron Symposium, 30 September-1 October 2019, Bilbao, Spain, and republished here under kind permission of the authors. 